\title{
A comparison of isomaltulose versus maltodextrin ingestion during soccer-specific exercise
}

\author{
Emma J. Stevenson ${ }^{1} \cdot$ Anthony Watson $^{2} \cdot$ Stephan Theis $^{3} \cdot$ Anja Holz $^{3} \cdot$ \\ Liam D. Harper ${ }^{4} \cdot$ Mark Russell $^{5}$
}

Received: 31 March 2017 / Accepted: 12 September 2017 / Published online: 19 September 2017

(C) The Author(s) 2017. This article is an open access publication

\begin{abstract}
Purpose The performance and physiological effects of isomaltulose and maltodextrin consumed intermittently during prolonged soccer-specific exercise were investigated.

Methods University soccer players $(n=22)$ performed 120 min of intermittent exercise while consuming $8 \%$ carbohydrate-electrolyte drinks (equivalent to $\sim 20 \mathrm{~g} \mathrm{~h}^{-1}$ ) containing maltodextrin (Glycaemic Index: 90-100), isomaltulose (Glycaemic Index: 32) or a carbohydrate-energy-free placebo in a manner replicating the practices of soccer players (i.e., during warm-up and half-time). Physical (sprinting, jumping) and technical (shooting, dribbling) performance was assessed.

Results Blood glucose and plasma insulin (both $P<0.001$ ) concentrations varied by trial with isomaltulose maintaining $>13 \%$ higher blood glucose concentrations between 75
\end{abstract}

Communicated by Peter Krustrup.

The original version of this article was revised due to a retrospective Open Access order.

Mark Russell

m.russell@leedstrinity.ac.uk

1 Institute of Cellular Medicine, Newcastle University, Newcastle upon Tyne, UK

2 Human Nutrition Research Centre, School of Agriculture, Food and Rural Development, Newcastle University, Newcastle upon Tyne, UK

3 BENEO-Institute, Obrigheim/Pfalz, Wormserstrasse 11, Obrigheim 67283, Germany

4 Human and Health Sciences, University of Huddersfield, Huddersfield, UK

5 School of Social and Health Sciences, Leeds Trinity University, Leeds LS18 5HD, UK and 90 min versus maltodextrin $(P<0.05)$. A decline in glycaemia at $60 \mathrm{~min}$ in maltodextrin was attenuated with isomaltulose ( -19 versus $-4 \% ; P=0.015)$. Carbohydrates attenuated elevations in plasma epinephrine concentrations $(P<0.05)$, but isomaltulose proved most effective at 90 and 120 min. Carbohydrates did not attenuate IL-6 increases or reductions in physical or technical performances (all $P>0.05)$. Ratings of abdominal discomfort were influenced by trial $(P<0.05)$ with lower values for both carbohydrates compared to PLA from 60 min onwards.

Conclusions Although carbohydrates $\left(\sim 20 \mathrm{~g} \mathrm{~h}^{-1}\right)$ did not attenuate performance reductions throughout prolonged soccer-specific exercise, isomaltulose maintained higher blood glucose at 75-90 min, lessened the magnitude of the exercise-induced rebound glycaemic response and attenuated epinephrine increases whilst maintaining similar abdominal discomfort values relative to maltodextrin. When limited opportunities exist to consume carbohydrates on competition-day, low-glycaemic isomaltulose may offer an alternative nutritional strategy for exercising soccer players.

Keywords Extra-time $\cdot$ Football $\cdot$ Half-time . Carbohydrate $\cdot$ Rebound hypoglycaemia

$\begin{array}{ll}\text { Abbreviations } \\ \text { ANOVA } & \text { Analysis of variance } \\ \text { CV } & \text { Coefficient of variation } \\ \text { ELISA } & \text { Enzyme-linked immunosorbent assay } \\ \text { GI } & \text { Glycaemic index } \\ \text { HR } & \text { Heart rate } \\ \text { HT } & \text { Half time } \\ \text { IL6 } & \text { Interleuken-6 } \\ \text { LSD } & \text { Least significant difference } \\ \text { MDX } & \text { Maltodextrin } \\ \text { MJ } & \text { Megajoules }\end{array}$




$\begin{array}{ll}\text { NEFA } & \text { Non-esterified fatty acids } \\ \text { PLA } & \text { Placebo } \\ \text { PSE } & \text { Palatinose } \\ \text { PT } & \text { Performance test } \\ \text { RPE } & \text { Rate of perceived exertion } \\ \text { SD } & \text { Standard deviation } \\ \text { SMS } & \text { Soccer match simulation }\end{array}$

\section{Introduction}

Soccer is a high-intensity intermittent team sport that typically requires players to complete 90 min of activity separated by a half-time (HT) break; however, when scores are equal at $90 \mathrm{~min}$ and an outright winner is required, extratime is played. Between 1998 and 2014, approximately $35 \%$ of knockout phase matches played in FIFA World Cup competitions have required the 30-min extra-time period (http://www.FIFA.com). Physical and skilled performance reduces throughout soccer-specific exercise of 90- (Harper et al. 2017; Russell et al. 2011a, 2012) and 120-min durations (Harper et al. 2014, 2016a, b). Therefore, interventions that maintain performance throughout the full duration of match-play are likely of interest when seeking to optimise the practices of soccer players.

Carbohydrate-electrolyte beverages are often recommended to soccer players before and during exercise in order to maintain glycaemia and fuel provision, and attenuate the risk of dehydration (Convertino et al. 1996; Thomas et al. 2016). Indeed, ergogenic effects have been observed following the regular ingestion (i.e., every $15 \mathrm{~min}$ ) of carbohydrates throughout $90 \mathrm{~min}$ of simulated match-play (Kingsley et al. 2014; Russell et al. 2012). However, regular fluid ingestion does not align with applied practices as professional players may only consume fluids during scheduled breaks in play (e.g., HT). The metabolic response to $\sim 68 \mathrm{~g}$ of total carbohydrates $\left(7 \mathrm{ml} \mathrm{kg}{ }^{-1}\right.$ body mass) consumed during $90 \mathrm{~min}$ of intermittent exercise does not seem to differ when ingested over two or six ingestion points (Clarke et al. 2008); however, owing to an omission of performance measures by Clarke et al. (2008), limited information exists to ascertain whether performance as opposed to metabolic responses are mediated by different feeding strategies.

Commercially available sports beverages generally consist of 6-10\% concentrations of carbohydrates, of which high-glycaemic index (GI) carbohydrate sources such as maltodextrin are common constituents. Paradoxically, highGI carbohydrates consumed within an hour of commencing a single bout of exercise may elicit rebound hypoglycaemia 15-30 min into subsequent activity (Chryssanthopoulos et al. 1994; Costill et al. 1977); a response for which the mechanisms, and performance consequences, are currently unclear (Jentjens and Jeukendrup 2003). In both simulated and actual soccer match-play, carbohydrate-electrolyte beverages ingested every $15 \mathrm{~min}$ during exercise and before each half, have also been shown to elicit a transient reduction in glycaemia at 45-60 min (Kingsley et al. 2014; Russell et al. 2012, 2014). Notably, Kingsley et al. (2014) observed hypoglycaemia (i.e., defined as $<3.8 \mathrm{mmol} \mathrm{l}^{-1}$ ) in $>50 \%$ of participants consuming carbohydrate beverages throughout simulated soccer match-play. Given the ergogenic effects of carbohydrates that maintain glycaemia throughout intermittent exercise (Harper et al. 2016a, 2017; Russell et al. 2012; Russell and Kingsley 2014), optimisation of match-day nutritional strategies is desirable for soccer players (Russell et al. 2015c).

The GI of the ingested carbohydrate appears to influence the occurrence of the rebound hypoglycaemic response at the onset of a single exercise bout (Jentjens and Jeukendrup 2003); possibly attributable to the degree of hyperinsulinemia observed post-ingestion (Costill et al. 1977). Isomaltulose is a disaccharide comprised of a glucose and fructose unit joined by an $\alpha-1,6$-glycosidic bond which is less readily hydrolysed by digestive enzymes in the human gastrointestinal tract when compared to the $\alpha-1,4$-linked monosaccharide units in maltodextrin. As a consequence of slower rates of hydrolysis (Dahlqvist et al. 1963) and subsequent absorption at the intestinal mucosa (MacDonald and Daniel 1983), isomaltulose results in a low-glycaemic and low-insulinemic response and prolongs the delivery of glucose to the systemic circulation. While it is acknowledged that prolonged versus expedited appearance of exogenous energy consumed in substantial amounts (i.e., $>60 \mathrm{~g} \mathrm{~h}^{-1}$ ) may affect gastric comfort and performance during exercise (Oosthuyse et al. 2015), such practices do not replicate the fluid-intake strategies of team sports players. Notably, fluid intake during competitive soccer may only occur during scheduled breaks in play (e.g., HT) and in the final stages of the warm-up and the immediate period before kick-off (Harper et al. 2017). Thus, fluid intake seldom occurs as often as has previously been examined (i.e., every $15 \mathrm{~min}$ ).

As no studies have investigated the effects of isomaltulose during soccer-specific exercise, and there is evidence that low-GI carbohydrates reduce the incidence of hypoglycaemic episodes when investigating the occurrence of rebound hypoglycaemia (Jentjens and Jeukendrup 2003), the aim of this study was to examine the performance and physiological effects of low-GI isomaltulose and high-GI maltodextrin consumed before and during 120 min of simulated soccer match-play using fluid intake patterns that better represent the demands of competition. The hypothesis associated with this study was that isomaltulose would prolong blood glucose availability and thereby influence performance and physiological responses during soccer-specific exercise. 


\section{Methods}

\section{Participants}

Following ethical approval for human studies (in accordance with the ethical standards laid down in the 1964 Declaration of Helsinki and its later amendments) and written informed consent being attained, 22 male university standard soccer players (age: $20 \pm 2$ years, mass: $73.0 \pm 7.9 \mathrm{~kg}$, stature: $1.79 \pm 0.07$ m, estimated $\dot{V} \mathrm{O}_{2 \max }: 54.8 \pm 3.1 \mathrm{ml} \mathrm{kg}^{-1} \mathrm{~min}^{-1}$ ) with $>1$ year's playing experience completed the study. Retrospective power analyses highlighted that the sample size was adequate for $>80 \%$ statistical power when detecting differences between physiological responses. Exclusion criteria included diagnosis of any significant medical condition or disorder that may have interfered with participation (e.g., cardiovascular disease, musculoskeletal disorders, diabetes mellitus).

\section{Experimental procedures}

All participants completed two preliminary visits to the laboratory followed by three main trials (Maltodextrin: MDX, high-GI; PALATINOSE ${ }^{\mathrm{TM}}$ : PSE, low-GI; placebo: PLA, no carbohydrates). Each player was advised to refrain from strenuous physical activity and caffeine consumption during the $72 \mathrm{~h}$ preceding all testing sessions and dietary intake was recorded for $48 \mathrm{~h}$ before each main trial (retrospectively analysed with: MicroDiet; Downlee Systems Ltd., High Peak, UK). A standardised evening meal was consumed on the night before each main trial (Energy content: $3.3 \mathrm{MJ}$, $92 \mathrm{~g}$ carbohydrate, $28 \mathrm{~g}$ fat and $37 \mathrm{~g}$ protein; representing $0.04-0.06 \mathrm{MJ} \mathrm{kg}^{-1}$ body mass).

\section{Preliminary testing}

Following arrival at the first preliminary testing session, players voided their bowels and bladder before body mass (model 876; Seca GmbH, Hamburg, Germany) and stature (Portable Stadiometer; Holtain Ltd, Wales, UK) were measured. A controlled warm up ( 20-min), including dynamic stretches and movements that progressed from low to moderate intensity, was then performed. Soccer skill practice $(\sim 5 \mathrm{~min}$ ) preceded performance of four 20 -m sprints (interspersed with $45 \mathrm{~s}$ active recovery) that progressed to nearmaximal speeds. Thereafter, maximal oxygen uptake was estimated (Ramsbottom et al. 1988) with a minimum value of $48.5 \mathrm{ml} \mathrm{kg}^{-1} \mathrm{~min}^{-1}$ required to allow completion of the 120 -min protocol. The second preliminary session habituated participants with the testing procedures of the main trials.

\section{Main experimental trials}

Players attended the laboratory at $08: 15 \mathrm{~h}$ following an overnight fast. Upon arrival, a mid-flow urine sample was provided and urine osmolality was measured (Model 3300 Micro-Osmometer; Advanced Instruments Inc., Norwood, MA, USA). Thereafter, a resting venous blood sample was taken before a standardised breakfast providing 10\% of the individual's daily energy requirement (Rice Krispies; Kellogg's, UK, semi-skimmed milk and $500 \mathrm{ml}$ of mineral water; $1.23 \pm 0.08 \mathrm{MJ}$, consisting of $52.0 \pm 3.3 \mathrm{~g}$ carbohydrate, $4.7 \pm 0.3 \mathrm{~g}$ fats and $10.9 \pm 0.7 \mathrm{~g}$ proteins) was consumed. Body mass and stature were then measured prior to $\sim 90$ min of rest; upon which a pre-exercise blood sample was taken. Players then commenced their final preparations before performing the same standardised warm-up as used in the preliminary testing. A 5-min period of passive recovery followed the end of the warm-up.

Measurements of physical and skilled performance preceded the start of exercise. Participants then performed $120 \mathrm{~min}$ of exercise and skills testing, consisting of two 45-min halves and two further 15-min periods (extra-time) of simulated match-play using a modified version of the Soccer Match Simulation (SMS; Russell et al. 2011b). Post-exercise assessments of performance, hydration status and body mass preceded a standardised cool down. All testing was performed indoors and environmental conditions were similar between trials (all $P>0.05$; temperature: $18.2 \pm 0.8^{\circ} \mathrm{C}$, pressure: $1033 \pm 25 \mathrm{mmHg}$, humidity: $38 \pm 4 \%$ ).

\section{Soccer match simulation}

The modified version of the SMS required players to cover $14.4 \mathrm{~km}$ (reflecting matches requiring extra-time; Russell et al. 2015a) at various running intensities, with backward and sideward movements over a 20 -m distance, while intermittently performing $15-\mathrm{m}$ sprints and soccer dribbling. Compared to the original SMS (Russell et al. 2011b), the assessment of soccer passing was omitted (such that more invasive blood samples could be taken) and extratime was required. In line with UEFA playing regulations, a 15-min passive recovery period (HT) separated the two 45-min halves, whereas a 2-min passive recovery period separated each extra-time half and a 5-min rest period preceded extra-time (Fig. 1). The repeatability of the responses to $120 \mathrm{~min}$ of the original SMS has been determined (Harper et al. 2016b).

\section{Performance testing}

Countermovement jump height, repeated sprint ability and soccer shooting performance were assessed on five occasions (performance test, PT) throughout each trial (i.e., Pre 
Fig. 1 Overview of main trial procedures
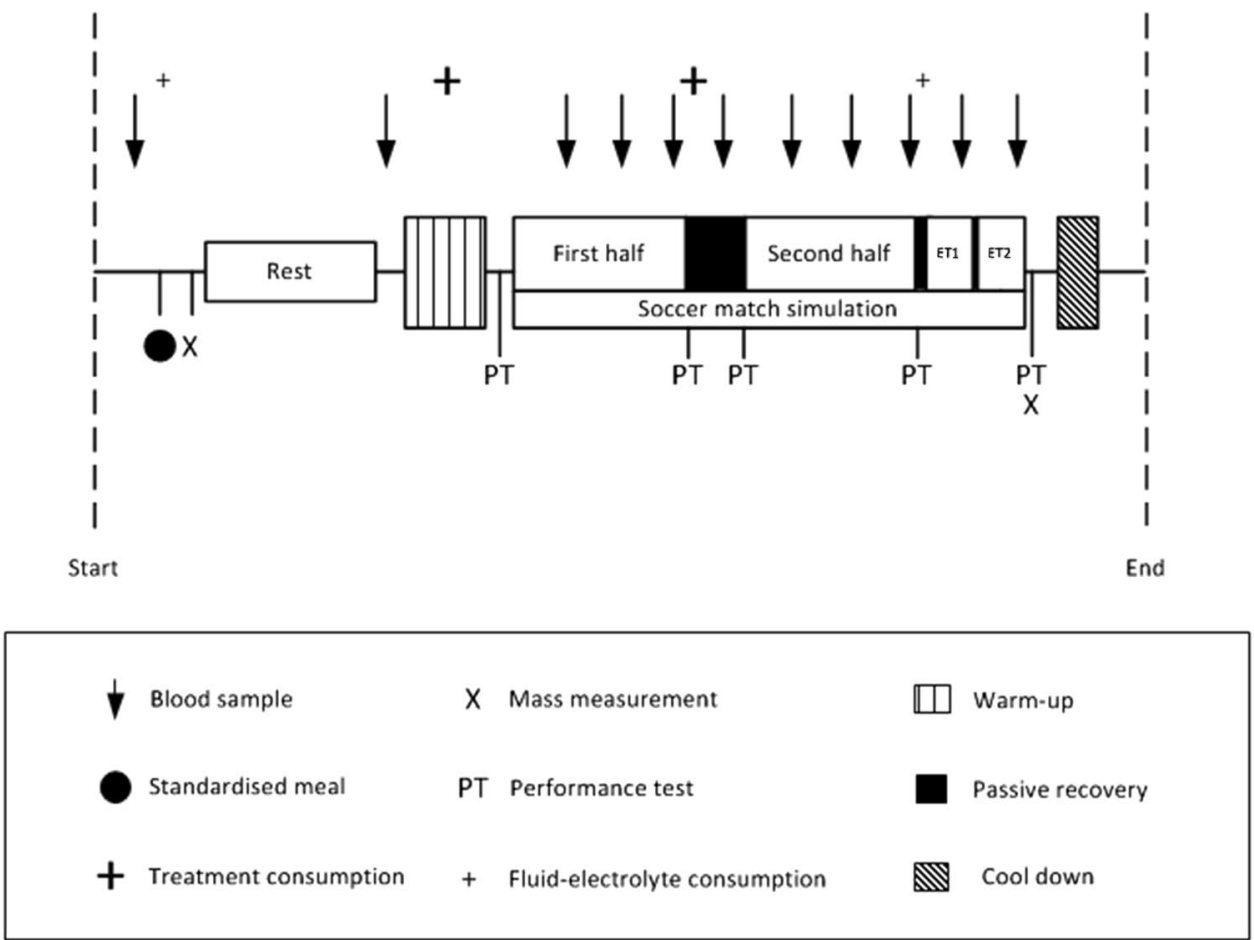

1st half, post 1 st half, pre 2 nd half, Post 2 nd half, post extratime; Fig. 1), whereas dribbling and $15 \mathrm{~m}$ sprint velocity were assessed throughout the SMS. Countermovement jump height was determined using an electronic system (OptoJump Next; Microgate SRL, Bolzano, Italy). Participants performed three repetitions (with $10 \mathrm{~s}$ of passive recovery) with the peak value used for subsequent analyses. Timed $15 \mathrm{~m}$ sprint performance (Brower Timing Systems, Utah, USA) was assessed throughout the SMS and values represent means per 15 min of exercise.

Repeated sprint maintenance was assessed from a standing start (from $0.3 \mathrm{~m}$ behind the first timing gate) and participants performed three maximal $20 \mathrm{~m}$ sprints, separated by $25 \mathrm{~s}$ of active recovery. The peak sprint velocity achieved during these three attempts was used to derive a sprint decrement index from the percentagewise reduction of sprint velocity between the slowest and fastest sprints.

Soccer shooting performance was assessed using methods similar to Russell et al. (2010). Balls (Mitre Promax: size 5; Mitre Sports International, London, England) released from behind participants towards a $1.5 \times 1.5$-m action zone, were required to be kicked towards one of four randomly illuminating targets placed in the corners of a standard adult soccer goal $(7.32 \times 2.44-\mathrm{m})$. The shooting assessments consisted of four attempts and participants were instructed to use the foot that they felt was most suitable to complete the task. The dribbling test has been described previously (Russell et al. 2010) and required participants to dribble a ball over a $20-\mathrm{m}$ track as fast and as accurately as possible.
The reliability and validity of these tests have been reported (Russell et al. 2010).

Skilled performance was analysed according to Russell et al. (2010) from $50 \mathrm{~Hz}$ video footage (DCR-HC96E; Sony Ltd, UK). Briefly, three outcome measures were calculated for each skill, including: precision (distance from target), percentage success and average ball speed. Precision was determined by digitising video footage (Kinovea version 0.8.15; Kinovea Org., France) to determine the distance of the centre of the ball from the centre of the target. Success in shooting was defined by shots taken within the confines of the action zone and where the ball impacted within the goal area. During dribbling, if a cone was touched by the ball or was not completed in the required direction, the cone was considered to be unsuccessfully negotiated. Dribbling success was defined as the percentage of cones negotiated successfully. Average ball speeds were calculated for all skills (Kinovea version 0.8.15; Kinovea Org., France) and shooting variables are expressed as an average at each time-point, whereas measures of dribbling performance are expressed per 15 min of exercise.

\section{Physiological testing}

Venous blood samples were taken from a cannula that was inserted in the cephalic vein (20 gauge; BD Venflon, BD, New Jersey, USA). While participants were in a recumbent position, venous blood was drawn at rest, pre-exercise (Pre), half-time (HT; $10 \mathrm{~min}$ into rest period) and every $15 \mathrm{~min}$ 
during exercise. Cannula patency was maintained by saline infusion $(\sim 5 \mathrm{ml})$. Blood was collected in two $6-\mathrm{ml}$ vacutainers (EDTA and Lipid Heparin) and a 2-ml luer at each time-point. Vacutainers were centrifuged at 3000 revolutions $\min ^{-1}$ for $10 \mathrm{~min}$ at $4{ }^{\circ} \mathrm{C}$ (Allegra X-22R; Beckman Coulter Ltd., California, USA) with the resultant plasma subsequently frozen at $-80{ }^{\circ} \mathrm{C}$. Blood from the luer was used to determine glucose and lactate concentrations (Biosen C-Line Clinic; EKF Diagnostics, Cardiff, UK).

Plasma volume changes were calculated at each timepoint by measurement of haemoglobin (Hemocue $\mathrm{Hb}$ 201 + System; Hemocue AB, Ängelholm, Sweden) and haematocrit and plasma osmolality was measured using freezing-point depression (Model 3300 Micro-Osmometer; Advanced Instruments Inc., Norwood, MA, USA). Urine and fluid-intake corrected mass changes were calculated between resting and post-exercise masses. Rates of perceived exertion (RPE; Borg 1973) and abdominal discomfort (modified from; Rowlands et al. 2008) were determined as averages over each 15-min interval. Heart rate (HR) was continuously recorded (Polar RS400; Polar Electro, Kempele, Finland) throughout each trial.

Plasma insulin (Insulin ELISA; IBL International GmbH, Hamburg, Germany: Intra-assay CV $=1.8-2.6 \%$ ), Interleukin-6 (IL-6; Interleukin-6 ELISA; IBL International GmbH, Hamburg, Germany: Intra-assay CV $=0.2-7.8 \%$ ) and epinephrine (IBL Adrenalin; IBL International GmbH, Hamburg, Germany: Intra-assay $\mathrm{CV}=6.8 \%$ ) concentrations were obtained by enzyme-linked immunosorbent assays (ELISA) techniques. Plasma epinephrine concentrations represent only the following: Pre, 45-min, HT, 60-, 90- and 120min time-points. Plasma glycerol and non-esterified fatty acid (NEFA) concentrations were measured using a clinical chemistry analyser (RX Daytona; Randox Laboratories Ltd., Co. Antrim, UK: NEFA intra-assay CV $=4.7-4.8 \%$, Glycerol intra-assay $\mathrm{CV}=0.9-1.3 \%$ ).

\section{Nutritional interventions}

Participants consumed 8\% drinks containing maltodextrin (MDX; GI: 90-100), or isomaltulose (PALATINOSETM, PSE; GI: 32) carbohydrate sources (Atkinson et al. 2008) or a fluid-electrolyte placebo (void of carbohydrate but containing an artificial sweetener; PLA) in a double-blind, randomised and cross-over fashion separated by $10 \pm 4$ days. Trial randomisation was carried out using a Latin-square design (http://www.randomization.com). Drinks were prepared and served in black opaque bottles by an independent person who was not involved in the main trial testing.

Professionally formulated beverage powders (Beneo $\mathrm{GmbH}$, Obrigheim, Germany) were mixed with the same fluid-electrolyte beverage (mineral water; Highland Spring; Highland Spring Group, Perthshire, Scotland) and were matched for taste (orange flavour), texture, colour and sweetness. All participants consumed mineral water with the pre-exercise meal $(500 \mathrm{ml})$ and before commencing the extra-time period of simulated match-play $\left(4.5 \mathrm{ml} \mathrm{kg}^{-1}\right.$ body mass). Treatment beverages were ingested during the soccer skill component of the warm-up $\left(4.5 \mathrm{ml} \mathrm{kg}^{-1}\right.$ body mass, corresponding to $0.36 \mathrm{~g} \mathrm{~kg}^{-1}$ body mass carbohydrates for the PSE and MDX trials) and at HT $\left(6 \mathrm{ml} \mathrm{kg}^{-1}\right.$ body mass, corresponding to $0.48 \mathrm{~g} \mathrm{~kg}^{-1}$ body mass carbohydrates for the PSE and MDX trials). No food or beverages other than that mentioned were consumed throughout testing. Participants were unable to distinguish between trials.

\section{Statistical analyses}

Statistical analyses were carried out using SPSS software (Version 21.0; SPSS Inc., IL, USA). All results are reported as the mean \pm standard deviation (SD). The level of statistical significance was set at $P \leq 0.05$. Data were sampled for normality and two-way repeated measures analyses of variance (ANOVA) established significant effects in the physiological and performance responses attributable to time and/or condition. Mauchly's test was consulted and Greenhouse-Geisser correction applied if the assumption of sphericity was violated. If a significant time $\times$ trial interaction existed, trial was deemed to have influenced the findings and simple main effects were examined using one-way repeated measures ANOVA. LSD corrected post-hoc tests isolated significant findings between trials.

\section{Results}

Pre-trial energy intake $\left(13.8 \pm 5.1 \mathrm{MJ} \mathrm{day}^{-1}\right)$, energy from individual macronutrients (carbohydrates: $45 \pm 7 \%$, fats: $34 \pm 7 \%$, proteins: $21 \pm 5 \%$ ) and resting plasma osmolality $\left(283 \pm 26 \mathrm{mOsmol} \mathrm{kg}{ }^{-1}\right)$ were similar between trials (all $P>0.05)$.

\section{Physiological responses}

Blood glucose concentrations were influenced by drink (time $\times$ trial interaction: $F_{(10,208)}=4.577, P<0.001$, partial-eta ${ }^{2}=0.179$; Fig. 2a). Despite similarities between trials before exercise, blood glucose was higher in PSE $(P=0.007)$, but not MDX $(P=0.168)$, at 15 min when compared to PLA. At HT, blood glucose concentrations in PSE $(P=0.001)$ and MDX $(P<0.001)$ were greater than PLA with a trend for a higher blood glucose peak in MDX compared to PSE $(P=0.058)$. The post HT decline in glycaemia following the onset of the second half was significantly greater with $\operatorname{MDX}\left(-19 \% ;-1.0 \pm 1.31 \mathrm{mmol} \mathrm{l}^{-1}\right)$ compared to PSE $\left(-4 \% ;-0.2 \pm 0.75 \mathrm{mmol} \mathrm{l}^{-1} ; P=0.015\right)$. Blood 
Fig. 2 Blood glucose (a) and plasma insulin (b) concentrations throughout the PSE (black solid line), MDX (black dashed line) and PLA (grey dashed line) trials $(n=22$, data are presented as mean $\pm \mathrm{SD}$ ). *Significant difference between PSE and PLA at corresponding time-point; a represents significant difference between PSE and MDX at corresponding time-point; $\mathbf{b}$ represents significant difference between MDX and PLA at corresponding time-point
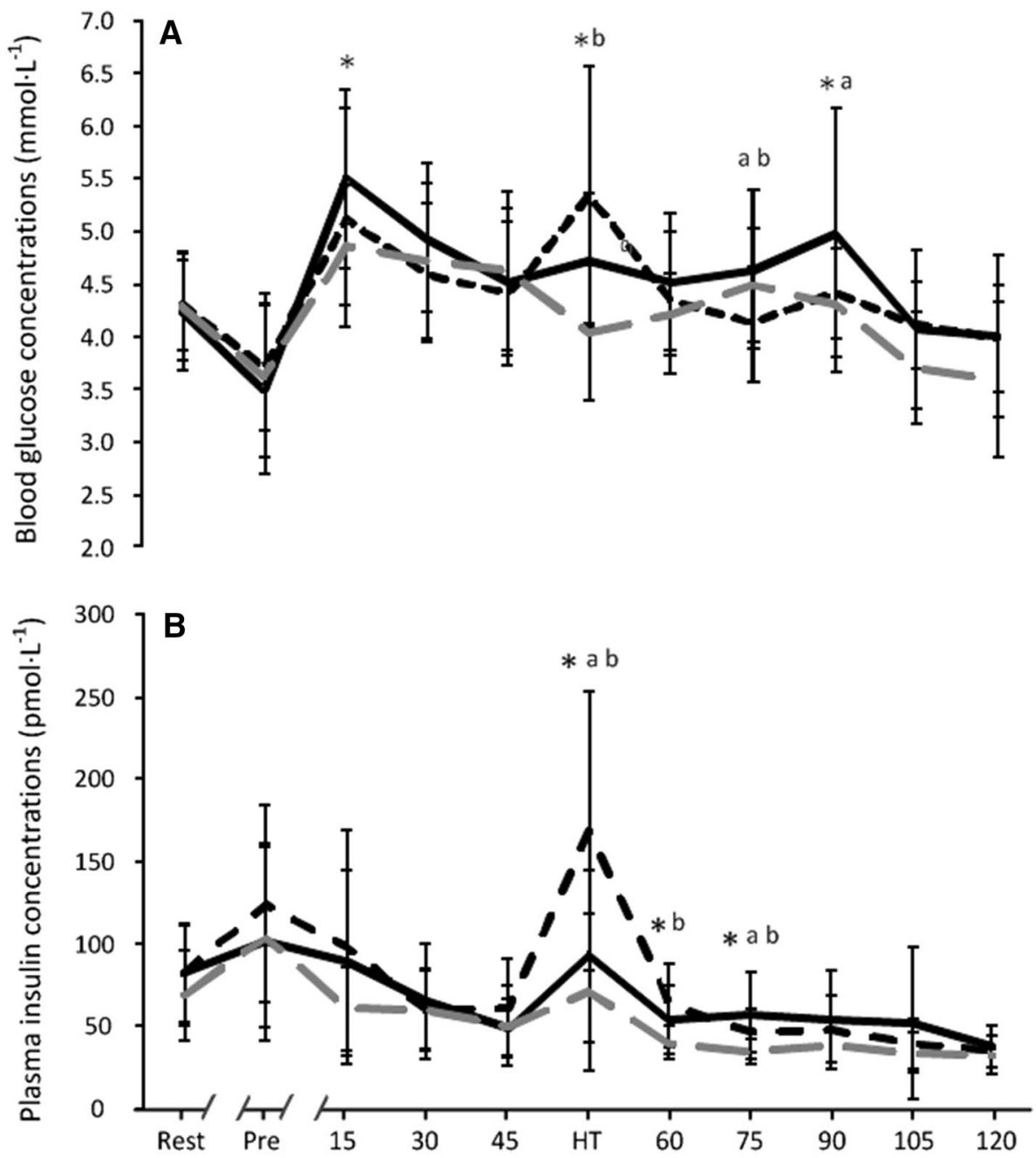

Timing (min unless otherwise stated) glucose concentrations at $60 \mathrm{~min}$ were similar $(P=0.239)$. At 75 and $90 \mathrm{~min}$, blood glucose was greatest in PSE versus MDX ( $P=0.010$ and $P=0.044$, respectively) with MDX values at $75 \mathrm{~min}$ also being lower than PLA $(P=0.038)$. No further differences were observed across trials.

Blood lactate concentrations were significantly influenced by exercise (time effect: $F_{(2,47)}=97.196, P<0.001$, partial-eta ${ }^{2}=0.822$; Table 1$)$ with values from $15 \mathrm{~min}$ being elevated over Pre (all $P<0.001$ ) but reducing throughout exercise. Values from $45 \mathrm{~min}$ were lower than the start of exercise (all $P<0.01$ ). No trial effects existed (time $\times$ trial interaction: $F_{(8,161)}=0.576, P=0.790$, partial-eta $\left.{ }^{2}=0.027\right)$.

Plasma insulin was similar between conditions until HT (time $\times$ trial interaction: $F_{(6,130)}=5.894, P<0.001$, partialeta $^{2}=0.219$; Fig. 2 b) where PSE $(P=0.031)$ and MDX $(P<0.001)$ demonstrated higher values compared to PLA; the rise in insulin was greatest in $\operatorname{MDX}(P=0.002$ versus PSE). At 60 and $75 \mathrm{~min}$, insulin concentrations remained elevated over PLA in $\operatorname{MDX}(P=0.001$ and $P=0.001$, respectively) and PSE ( $P=0.004$ and $P<0.001$, respectively). Differences between MDX and PSE at $75 \mathrm{~min}$ $(P=0.040)$ were negated at $90 \mathrm{~min}$, with no differences observed between carbohydrate trials at the end of exercise.

Plasma epinephrine was influenced by trial and exercise (time $\times$ trial interaction: $F_{(2,42)}=12.342, P<0.001$, partialeta $^{2}=0.370$; Table 1) with similar concentrations between conditions until $90 \mathrm{~min}$ where PSE $(P=0.004)$, but not $\operatorname{MDX}(P=0.108)$, attenuated the rise seen in PLA. Epinephrine values were lower in PSE compared to MDX at 90 min $(P=0.030)$. At $120 \mathrm{~min}$, both $\operatorname{MDX}(P=0.002)$ and PSE $(P<0.001)$ attenuated the rise observed in PLA with a trend for lower epinephrine concentrations with PSE compared to $\operatorname{MDX}(P=0.073)$.

Glycerol was influenced by time and trial (interaction: $F_{(7,141)}=9.025, P<0.001$, partial-eta ${ }^{2}=0.301$; Table 1$)$. No between-trial differences existed until 45 min where MDX $(P=0.017)$ and PSE $(P=0.028)$ attenuated the rise observed in PLA. At HT, glycerol concentrations were similar 


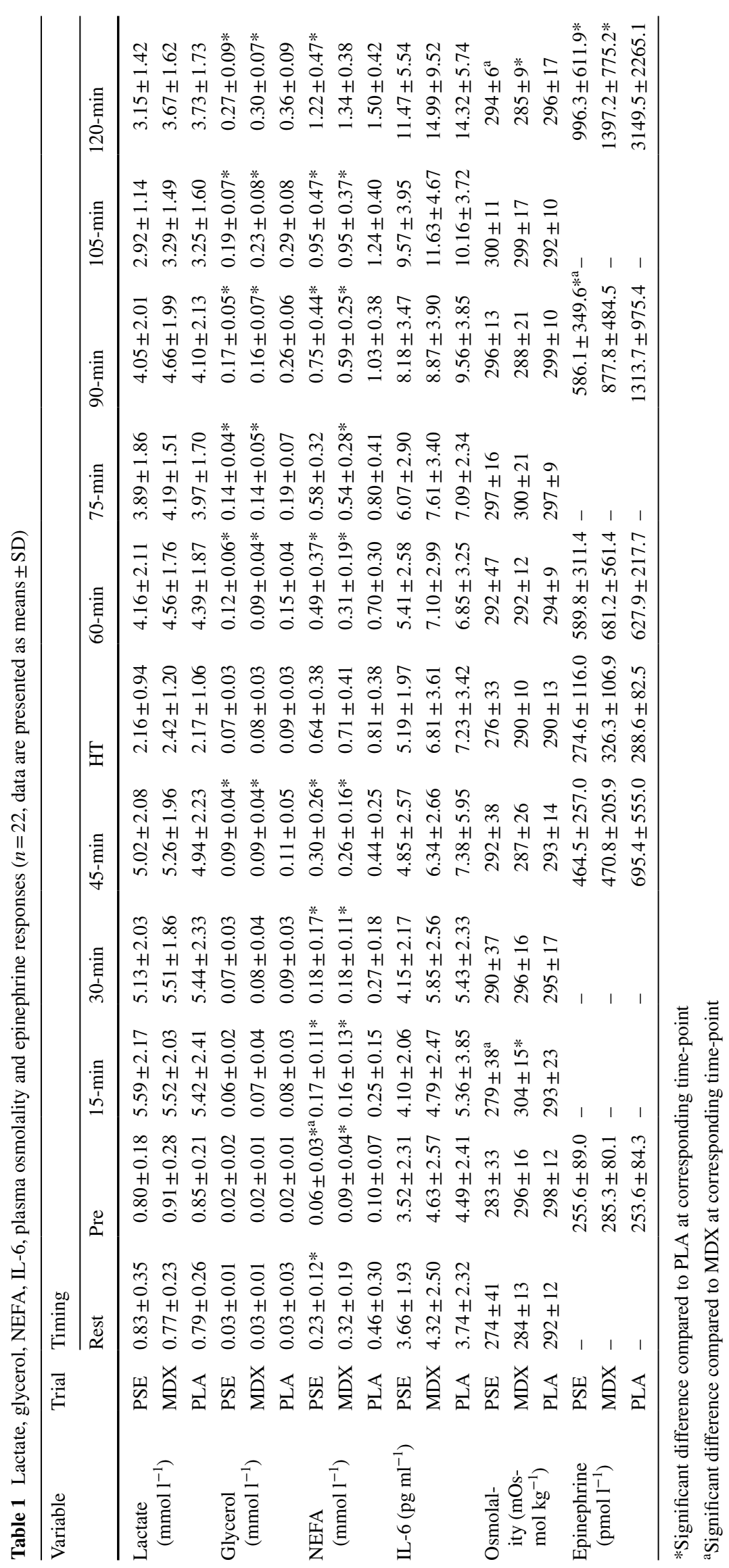


between conditions but from 60 min onwards both MDX (all $P<0.05$ ) and PSE (all $P<0.05$ ) attenuated the rise in glycerol seen in PLA with no difference between carbohydrate trials (all $P>0.05$ ). Similarly, NEFA concentrations were influenced by drink (time $\times$ trial interaction: $F_{(7,149)}=2.517$, $P=0.017$, partial-eta ${ }^{2}=0.107$; Table 1 ) with greater values observed in PLA at all time-points except for HT.

Exercise influenced the IL-6 response (time effect: $F_{(4,73)}=82.708, P<0.001$, partial-eta ${ }^{2}=0.798$ ) with significant increases from resting values observed at all time-points (all $P \leq 0.001$ ). Further increases in IL-6 were observed during extra time (i.e., at 105 and $120 \mathrm{~min}$ ) relative to $90 \mathrm{~min}$ (both $P \leq 0.001$ ). No interaction between time and condition was present (time $\times$ trial interaction: $F_{(4,93)}=0.979$, $P=0.429$, partial-eta ${ }^{2}=0.045$; Table 1$)$. However, there was a trend for IL- 6 concentrations being overall reduced (trial effect: $F_{(2,33)}=3.324, P=0.060$, partial-eta $\left.{ }^{2}=0.137\right)$ with PSE compared to MDX $(P=0.014)$ and PLA $(P=0.020)$.

Plasma osmolality varied according to trial (time $\times$ trial interaction: $F_{(5,110)}=2.611, P=0.026$, partial-eta ${ }^{2}=0.111$; Table 1) with values at $15 \mathrm{~min}$ being lower in PSE when compared to $\operatorname{MDX}(P=0.014)$. Notably, osmolality in PLA was also lower than MDX $(P=0.034)$ at $15 \mathrm{~min}$. No further differences were observed until 120 min (MDX versus PSE: $P<0.001$, MDX versus PLA: $P=0.006)$. Body mass reduced by $1.82 \pm 0.97,1.63 \pm 0.48$ and $1.82 \pm 0.67 \mathrm{~kg}$ throughout PSE, MDX and PLA, respectively, but the magnitude of change was similar between trials (time $\times$ trial interaction: $F_{(1,30)}=0.806, P=0.411$, partial-eta ${ }^{2}=0.037$ ).

Abdominal discomfort varied throughout exercise according to trial (time $\times$ trial interaction: $F_{(7,139)}=2.418$, $P=0.025$, partial-eta ${ }^{2}=0.103$; Table 2 ). Although posthoc tests were unable to locate these differences, ratings of abdominal discomfort were consistently lower with both carbohydrates compared to PLA from 60 min onwards.
Exercise influenced abdominal discomfort (time effect: $F_{(2,38)}=32.736, P<0.001$, partial-eta ${ }^{2}=0.609$ ) with significant increases throughout exercise from 15 min onwards (all $P<0.001$ ) and during extra-time (i.e., $105-120 \mathrm{~min}$ versus 75-90 min: $P<0.001)$.

Exercise (time effect: $F_{(2,33)}=86.330, P<0.001$, partial-eta ${ }^{2}=0.804$ ), but not trial (time $\times$ trial interaction: $F_{(5,98)}=0.326, P=0.886$, partial-eta ${ }^{2}=0.015$; Table 2), influenced RPE after $0-15$ min (all $P<0.05$ ). Further increases were observed in extra-time relative to $75-90 \mathrm{~min}$ $(P<0.001)$. Mean and peak HR were comparable between conditions (time $\times$ trial interaction: $F_{(6,133)}=0.995$, $P=0.434$, partial-eta ${ }^{2}=0.045$; time $\times$ trial interaction: $F_{(4,88)}=1.056, P=0.385$, partial-eta ${ }^{2}=0.048$, respectively; Table 2) with greater values observed at the end of exercise compared to the first 15 min (mean HR: $P=0.022$; peak HR: $P=0.012$ ).

\section{Physical performance}

Exercise reduced 20-m repeated sprint performance (time effect: $F_{(4,84)}=8.234, P<0.001$, partial-eta ${ }^{2}=0.282$ ) with sprint decrement values from Pre 2 nd half onwards being greater than Pre 1 st half (all $P<0.05$ ). Repeated sprint performance reduced similarly throughout exercise between trials (time $\times$ trial interaction: $F_{(4,87)}=1.552, P=0.193$, partial-eta ${ }^{2}=0.069$; Table 3 ). Exercise (time effect: $F_{(3,53)}=9.087, P<0.001$, partial-eta $\left.{ }^{2}=0.302\right)$, but not trial (time $\times$ trial interaction: $F_{(5,100)}=1.098, P=0.365$, partial-eta ${ }^{2}=0.050$; Table 3 ), influenced jump height. A transient reduction in jump height compared to Pre 1st half occurred after HT (i.e., at Pre 2nd half; $P=0.001$ ). Jump performance reduced further after the extra-time period with jump height being lower than Pre 1st half values $(P=0.029)$ and also lower compared to Post 2 nd half

Table 2 Peak HR, mean HR, RPE and abdominal discomfort responses ( $n=22$, data are presented as means \pm SD)

\begin{tabular}{|c|c|c|c|c|c|c|c|c|c|}
\hline \multirow[t]{2}{*}{ Variable } & \multirow[t]{2}{*}{ Trial } & \multicolumn{8}{|l|}{ Timing } \\
\hline & & $0-15 \min$ & $15-30 \mathrm{~min}$ & $30-45 \mathrm{~min}$ & $45-60 \mathrm{~min}$ & $60-75 \mathrm{~min}$ & $75-90 \mathrm{~min}$ & $90-105 \mathrm{~min}$ & $105-120 \mathrm{~min}$ \\
\hline \multirow[t]{3}{*}{ Peak HR (beats $\min ^{-1}$ ) } & PSE & $184 \pm 9$ & $184 \pm 9$ & $183 \pm 8$ & $184 \pm 7$ & $188 \pm 13$ & $188 \pm 13$ & $184 \pm 8$ & $189 \pm 12$ \\
\hline & MDX & $188 \pm 10$ & $187 \pm 8$ & $186 \pm 8$ & $186 \pm 9$ & $188 \pm 9$ & $187 \pm 9$ & $186 \pm 10$ & $189 \pm 9$ \\
\hline & PLA & $184 \pm 11$ & $183 \pm 11$ & $184 \pm 10$ & $183 \pm 10$ & $185 \pm 10$ & $185 \pm 9$ & $184 \pm 9$ & $187 \pm 10$ \\
\hline \multirow[t]{3}{*}{ Mean HR (beats $\min ^{-1}$ ) } & PSE & $159 \pm 9$ & $158 \pm 11$ & $159 \pm 10$ & $160 \pm 7$ & $158 \pm 10$ & $160 \pm 11$ & $159 \pm 9$ & $161 \pm 10$ \\
\hline & MDX & $164 \pm 11$ & $162 \pm 11$ & $163 \pm 10$ & $161 \pm 11$ & $163 \pm 11$ & $162 \pm 11$ & $164 \pm 10$ & $163 \pm 10$ \\
\hline & PLA & $161 \pm 13$ & $159 \pm 15$ & $159 \pm 16$ & $160 \pm 11$ & $161 \pm 14$ & $161 \pm 12$ & $162 \pm 12$ & $164 \pm 13$ \\
\hline \multirow[t]{3}{*}{ RPE (units) } & PSE & $11.6 \pm 1.9$ & $12.8 \pm 1.6$ & $13.4 \pm 1.3$ & $13.2 \pm 1.4$ & $14.5 \pm 1.1$ & $15.1 \pm 1.4$ & $15.4 \pm 1.6$ & $16.7 \pm 1.9$ \\
\hline & MDX & $11.3 \pm 1.8$ & $12.6 \pm 1.4$ & $13.3 \pm 1.4$ & $12.7 \pm 1.6$ & $14.1 \pm 1.6$ & $14.8 \pm 1.6$ & $15.2 \pm 2.1$ & $16.6 \pm 2.1$ \\
\hline & PLA & $11.6 \pm 2.1$ & $12.9 \pm 2.0$ & $13.5 \pm 1.8$ & $13.2 \pm 1.9$ & $14.4 \pm 2.0$ & $15.1 \pm 1.9$ & $15.5 \pm 1.9$ & $16.8 \pm 2.0$ \\
\hline \multirow[t]{3}{*}{ Abdominal discomfort (units) } & PSE & $1.6 \pm 1.4$ & $2.3 \pm 1.8$ & $2.4 \pm 1.6$ & $2.3 \pm 1.5$ & $2.5 \pm 1.7$ & $2.9 \pm 1.8$ & $3.2 \pm 1.8$ & $3.7 \pm 2.0$ \\
\hline & MDX & $1.6 \pm 0.9$ & $2.2 \pm 1.3$ & $2.5 \pm 1.4$ & $2.3 \pm 1.5$ & $2.5 \pm 1.5$ & $2.9 \pm 1.7$ & $3.1 \pm 1.8$ & $4.0 \pm 2.2$ \\
\hline & PLA & $1.6 \pm 1.2$ & $2.2 \pm 1.4$ & $2.5 \pm 1.5$ & $2.4 \pm 1.5$ & $3.0 \pm 1.6$ & $3.5 \pm 1.8$ & $3.6 \pm 1.9$ & $4.4 \pm 2.3$ \\
\hline
\end{tabular}


Table 3 Peak 20-m sprint velocity, sprint decrement index, jump height, shot speed, shot precision and shot success responses $(n=22$, data are presented as means $\pm \mathrm{SD}$ )

\begin{tabular}{|c|c|c|c|c|c|c|}
\hline \multirow[t]{2}{*}{ Variable } & \multirow[t]{2}{*}{ Trial } & \multicolumn{5}{|l|}{ Timing } \\
\hline & & Pre 1st half & Post 1st half & Pre 2nd half & Post 2nd half & Post extra-time \\
\hline \multirow[t]{3}{*}{ Peak 20-m sprint velocity $\left(\mathrm{m} \mathrm{s}^{-1}\right)$} & PSE & $6.27 \pm 0.27$ & $6.15 \pm 0.33$ & $5.98 \pm 0.32$ & $5.98 \pm 0.38$ & $5.82 \pm 0.51$ \\
\hline & MDX & $6.24 \pm 0.27$ & $6.12 \pm 0.31$ & $5.98 \pm 0.27$ & $5.97 \pm 0.38$ & $5.77 \pm 0.53$ \\
\hline & PLA & $6.26 \pm 0.29$ & $6.14 \pm 0.29$ & $6.00 \pm 0.29$ & $6.11 \pm 0.34$ & $5.84 \pm 0.47$ \\
\hline \multirow[t]{3}{*}{ Sprint decrement index (\%) } & PSE & $3.5 \pm 2.1$ & $3.0 \pm 1.4$ & $4.8 \pm 4.0$ & $5.1 \pm 2.8$ & $5.8 \pm 4.1$ \\
\hline & MDX & $3.5 \pm 2.2$ & $5.1 \pm 3.5$ & $4.6 \pm 2.8$ & $3.9 \pm 2.5$ & $5.6 \pm 3.8$ \\
\hline & PLA & $3.8 \pm 2.1$ & $3.9 \pm 2.7$ & $4.1 \pm 3.0$ & $6.4 \pm 4.0$ & $6.5 \pm 5.2$ \\
\hline \multirow[t]{3}{*}{ Jump height $(\mathrm{cm})$} & PSE & $34.5 \pm 4.4$ & $34.0 \pm 4.4$ & $32.6 \pm 5.0$ & $33.2 \pm 4.3$ & $32.1 \pm 5.3$ \\
\hline & MDX & $33.9 \pm 4.8$ & $34.1 \pm 5.7$ & $32.3 \pm 5.3$ & $33.7 \pm 5.8$ & $33.1 \pm 6.0$ \\
\hline & PLA & $33.7 \pm 4.8$ & $34.7 \pm 5.3$ & $32.6 \pm 5.6$ & $33.9 \pm 6.1$ & $33.2 \pm 6.1$ \\
\hline \multirow[t]{3}{*}{ Shot speed $\left(\mathrm{m} \mathrm{s}^{-1}\right)$} & PSE & $18.9 \pm 2.0$ & $18.7 \pm 2.0$ & $18.0 \pm 2.1$ & $18.5 \pm 1.9$ & $18.0 \pm 1.9$ \\
\hline & MDX & $18.2 \pm 2.2$ & $17.9 \pm 1.9$ & $18.2 \pm 1.7$ & $17.6 \pm 1.6$ & $17.8 \pm 2.0$ \\
\hline & PLA & $18.7 \pm 2.3$ & $18.3 \pm 2.4$ & $17.9 \pm 2.5$ & $18.4 \pm 2.3$ & $17.6 \pm 2.5$ \\
\hline \multirow[t]{3}{*}{ Shot precision $(\mathrm{cm})$} & PSE & $132 \pm 54$ & $138 \pm 70$ & $146 \pm 67$ & $121 \pm 36$ & $156 \pm 64$ \\
\hline & MDX & $139 \pm 53$ & $118 \pm 62$ & $153 \pm 74$ & $121 \pm 54$ & $128 \pm 53$ \\
\hline & PLA & $124 \pm 52$ & $116 \pm 51$ & $137 \pm 64$ & $143 \pm 52$ & $120 \pm 63$ \\
\hline \multirow[t]{3}{*}{ Shot success (\%) } & PSE & $67 \pm 25$ & $65 \pm 21$ & $76 \pm 20$ & $78 \pm 21$ & $69 \pm 24$ \\
\hline & MDX & $66 \pm 21$ & $67 \pm 20$ & $64 \pm 29$ & $72 \pm 22$ & $74 \pm 24$ \\
\hline & PLA & $67 \pm 22$ & $69 \pm 20$ & $74 \pm 25$ & $75 \pm 20$ & $66 \pm 20$ \\
\hline
\end{tabular}

$(P=0.024)$. Mean $15 \mathrm{~m}$ sprint velocity reduced throughout exercise (time effect: $F_{(3,66)}=96.872, P<0.001$, partial-eta ${ }^{2}=0.822$ ), but no effect of drink was observed (time $\times$ trial interaction: $F_{(5,113)}=0.754, P=0.594$, partial-eta ${ }^{2}=0.035$; Table 4 ). All sprints performed from 15-30 min onwards were slower than 0-15 min values (all $P<0.05$ ) and further decrements were observed during the extra-time period relative to $75-90 \mathrm{~min}(P<0.001)$.

\section{Skilled performance}

Shot precision (time effect: $F_{(3,61)}=1.256, P=0.297$, partial-eta $^{2}=0.056$ ) and success (time effect: $F_{(4,84)}=1.350$, $P=0.258$, partial-eta ${ }^{2}=0.060$ ) were unaffected by exercise, whereas there was a trend for shot speed being reduced over the trial duration (time effect: $F_{(2,40)}=3.174, P=0.055$, partial-eta $\left.^{2}=0.131\right)$. Ball speed was $2.9 \%$ slower at Pre 2 nd half when compared to shots taken before exercise $(P=0.039)$.

Table 4 Mean 15-m sprint velocity, dribbling speed, dribbling precision and dribbling success responses $(n=22$, data are presented as means $\pm \mathrm{SD})$

\begin{tabular}{|c|c|c|c|c|c|c|c|c|c|}
\hline \multirow[t]{2}{*}{ Variable } & \multirow[t]{2}{*}{ Trial } & \multicolumn{8}{|l|}{ Timing } \\
\hline & & $0-15 \min$ & $15-30 \mathrm{~min}$ & $30-45 \min$ & $45-60 \mathrm{~min}$ & $60-75 \min$ & $75-90 \mathrm{~min}$ & 90-105 min & $105-120 \mathrm{~min}$ \\
\hline \multirow{3}{*}{$\begin{array}{l}\text { Mean 15-m sprint velocity } \\
\left(\mathrm{m} \mathrm{s}^{-1}\right)\end{array}$} & PSE & $5.58 \pm 0.36$ & $5.48 \pm 0.35$ & $5.48 \pm 0.34$ & $5.40 \pm 0.35$ & $5.28 \pm 0.38$ & $5.19 \pm 0.41$ & $5.09 \pm 0.42$ & $4.97 \pm 0.50$ \\
\hline & MDX & $5.54 \pm 0.37$ & $5.43 \pm 0.39$ & $5.37 \pm 0.41$ & $5.29 \pm 0.32$ & $5.21 \pm 0.35$ & $5.15 \pm 0.37$ & $5.00 \pm 0.40$ & $4.84 \pm 0.48$ \\
\hline & PLA & $5.62 \pm 0.38$ & $5.56 \pm 0.43$ & $5.45 \pm 0.41$ & $5.44 \pm 0.39$ & $5.26 \pm 0.31$ & $5.16 \pm 0.33$ & $5.06 \pm 0.30$ & $4.89 \pm 0.32$ \\
\hline \multirow[t]{3}{*}{ Dribbling speed $\left(\mathrm{m} \mathrm{s}^{-1}\right)$} & PSE & $3.2 \pm 0.3$ & $3.2 \pm 0.2$ & $3.2 \pm 0.4$ & $3.2 \pm 0.2$ & $3.3 \pm 0.3$ & $3.2 \pm 0.4$ & $3.3 \pm 0.3$ & $3.0 \pm 0.3$ \\
\hline & MDX & $3.3 \pm 0.4$ & $3.2 \pm 0.2$ & $3.2 \pm 0.3$ & $3.3 \pm 0.4$ & $3.3 \pm 0.4$ & $3.2 \pm 0.4$ & $3.2 \pm 0.3$ & $3.1 \pm 0.3$ \\
\hline & PLA & $3.2 \pm 0.3$ & $3.2 \pm 0.2$ & $3.1 \pm 0.2$ & $3.2 \pm 0.2$ & $3.2 \pm 0.2$ & $3.2 \pm 0.3$ & $3.1 \pm 0.2$ & $3.1 \pm 0.3$ \\
\hline \multirow[t]{3}{*}{ Dribbling precision $(\mathrm{cm})$} & PSE & $42 \pm 13$ & $41 \pm 10$ & $40 \pm 11$ & $40 \pm 10$ & $35 \pm 9$ & $35 \pm 8$ & $37 \pm 6$ & $37 \pm 11$ \\
\hline & MDX & $44 \pm 8$ & $40 \pm 8$ & $41 \pm 8$ & $38 \pm 8$ & $36 \pm 10$ & $35 \pm 10$ & $37 \pm 9$ & $36 \pm 9$ \\
\hline & PLA & $41 \pm 8$ & $37 \pm 8$ & $37 \pm 8$ & $34 \pm 7$ & $33 \pm 8$ & $35 \pm 9$ & $34 \pm 8$ & $34 \pm 7$ \\
\hline \multirow[t]{3}{*}{ Dribbling success (\%) } & PSE & $91 \pm 9$ & $80 \pm 15$ & $92 \pm 11$ & $93 \pm 6$ & $88 \pm 11$ & $86 \pm 12$ & $89 \pm 8$ & $79 \pm 14$ \\
\hline & MDX & $90 \pm 8$ & $90 \pm 13$ & $90 \pm 13$ & $94 \pm 8$ & $93 \pm 8$ & $90 \pm 13$ & $90 \pm 11$ & $87 \pm 10$ \\
\hline & PLA & $90 \pm 8$ & $89 \pm 8$ & $91 \pm 11$ & $93 \pm 8$ & $86 \pm 15$ & $86 \pm 13$ & $88 \pm 11$ & $90 \pm 8$ \\
\hline
\end{tabular}


Shot speeds Post extra-time were 4.3\% ( $P=0.049)$ slower than Pre values and $2.9 \%(P=0.039)$ slower than Post 2 nd half. Shot success was slightly higher with PSE compared to MDX at Pre and Post 2nd half (76 versus $64 \%$ and 78 versus $72 \%$, respectively; Table 3). After 90 min (i.e., at Post 2nd half), more players scored $100 \%$ of shots when they had taken PSE (41\%) rather than MDX (23\%) or PLA (23\%). However, the effects of drinks on soccer shooting performance throughout exercise were non-significant (speed: time $\times$ trial interaction: $F_{(8,168)}=1.381, P=0.208$, partial-eta ${ }^{2}=0.062$; precision: time $\times$ trial interaction: $F_{(8,168)}=1.753, P=0.090$, partial-eta ${ }^{2}=0.077$; success: time $\times$ trial interaction: $F_{(8,168)}=0.891, P=0.525$, partialeta $^{2}=0.041$; Table 3 ).

Exercise reduced dribble speed (time effect: $F_{(7,147)}=5.774, P<0.001$, partial-eta $\left.{ }^{2}=0.216\right)$, with dribbles performed at 30-45 $\min (P=0.008)$ and throughout extra-time (i.e., at $90-105-\mathrm{min} ; P=0.067$, and $105-120 \mathrm{~min}$; $P<0.001$ ), being slower when compared to $0-15 \mathrm{~min}$. Dribble speed reduced further during extra-time (i.e., 105-120-min) when compared to 75-90 $\min (P=0.002)$. Dribbling precision improved throughout exercise (time effect: $F_{(4,92)}=16.777, P<0.001$, partial-eta ${ }^{2}=0.444$ ) with dribbles performed from 30-45 min onwards being closer to the target when compared to $0-15 \min$ (all $P \leq 0.029$ ). Dribble success reduced throughout exercise (time effect: $F_{(7,147)}=6.380, P<0.001$, partial-eta $\left.{ }^{2}=0.233\right)$ as dribbles were $5.2 \%$ less successful at the end of extra-time versus 0-15 $\min (P<0.001)$. Dribbling performances throughout exercise were comparable between beverages (time $\times$ trial interaction for speed: $F_{(7,137)}=0.886, P=0.514$, partial-eta ${ }^{2}=0.041$, time $\times$ trial interaction for precision: $F_{(6,120)}=0.662, P=0.674$, partial-eta ${ }^{2}=0.031$; Table 4$)$, yet an interaction existed for success (time $\times$ trial interaction $F_{(7,138)}=2.133, P=0.048$, partial-eta ${ }^{2}=0.092$; Table 4$)$.

\section{Discussion}

Although carbohydrates did not attenuate performance declines throughout prolonged simulated soccer matchplay, physiological responses differed according to the ingestion of either $\sim 20 \mathrm{~g} \mathrm{~h}^{-1}$ of the low-GI carbohydrate isomaltulose or high-GI maltodextrin. When compared to MDX, and while eliciting similar abdominal discomfort values, blood glucose concentrations were greater between 75 and 90 min in PSE and the magnitude of a transient decline in glycaemia observed at the start of the second half (i.e., $60 \mathrm{~min}$ ) was lessened. Moreover, PSE was measurably more effective than MDX in lowering the epinephrine response to prolonged exercise. Thus, when limited opportunities exist to supply exogenous energy during prolonged intermittent exercise, low-GI carbohydrates may offer an alternative strategy to high-GI carbohydrate consumption.

In an attempt to maintain glycaemia and to enhance exogenous carbohydrate oxidation (Coyle et al. 1986) team sports athletes are recommended to consume carbohydrate-electrolyte beverages before and during exercise (Convertino et al. 1996; Thomas et al. 2016). Paradoxically, a transient lowering of blood glucose concentrations occurs in the initial stages of the second half when carbohydrate is consumed frequently (Bangsbo et al. 2007; Kingsley et al. 2014; Krustrup et al. 2006; Russell et al. 2012, 2014) and likely reflects physiological differences between the effects of carbohydrates consumed in either the passive (i.e., HT; insulin secretion attempts to normalise blood glucose concentrations by decreasing lipolysis and facilitating glucose uptake) versus active (i.e., exercise; counter-regulatory hormones dampen the insulin response) states combined with the insulin-independent glucose uptake that occurs after a prior exercise bout. In studies aiming to elicit rebound hypoglycaemia, consuming low-GI carbohydrates reduced the number of participants experiencing blood glucose concentrations $<3.5 \mathrm{mmol} \mathrm{l}^{-1}$, a finding attributed to the degree of hyperinsulinemia resulting from pre-exercise carbohydrate ingestion (Costill et al. 1977; Jentjens and Jeukendrup 2003). Indeed, we observed lower HT insulin concentrations in PSE when compared to MDX (Fig. 2b) and fewer participants experienced hypoglycaemia (defined as glucose concentrations $<3.8 \mathrm{mmol} \mathrm{l}^{-1}$; Balijepalli et al. 2017; Smith et al. 2016) at $60 \mathrm{~min}$ (18 versus 27\%). Moreover, the change in glycaemia from HT was also less in PSE compared to MDX $\left(-4 \% ;-0.2 \pm 0.75 \mathrm{mmol} \mathrm{l}^{-1}\right.$ versus $-19 \%$; $-1.0 \pm 1.31 \mathrm{mmol}^{-1} ; P=0.015$ ) at $60 \mathrm{~min}$ (Fig. 2a). Although the effects of rapid reductions in glycaemia are unclear, blood glucose concentrations appeared better maintained at the start of the second half of soccer-specific exercise when low-GI carbohydrates were consumed.

Although glycogen measurements were not taken in the present study, it is likely that the additional demands of extra-time further challenged muscle and liver glycogen reserves (Foskett et al. 2008). Metabolites associated with greater net muscle glycogen utilisation such as plasma epinephrine and IL-6 (Febbraio et al. 1998; Helge et al. 2003) which were significantly elevated over 90 -min values at 120 min would support this supposition. Likewise, postexercise NEFA and glycerol responses are indicative of significant taxing of endogenous energy stores. As fatigue during high-intensity exercise has previously been attributed to muscle glycogen depletion (Foskett et al. 2008); our findings further support the additive effects of the soccer extra-time period when compared to the previous 90 min (Harper et al. 2016a). Notably, carbohydrate ingestion has been shown to blunt epinephrine release during prolonged exercise (Felig et al. 1982; Fritzsche et al. 2000), but this response appears 
minimised during $90 \mathrm{~min}$ of exercise when the carbohydrate dose is low ( $13 \mathrm{~g} \mathrm{~h}^{-1}$; Clarke et al. 2008). Ingestion of $\sim 20 \mathrm{~g} \mathrm{~h}^{-1}$ of carbohydrate in the current study, albeit a low but practically applicable dose, yielded reductions in epinephrine concentrations at $90 \mathrm{~min}$ in PSE and at $120 \mathrm{~min}$ in both PSE and MDX (with epinephrine levels being lower in PSE compared to MDX; $P=0.030$ and $P=0.073$ at 90 and $120 \mathrm{~min}$, respectively). The practical implications of this blunted response are unclear as performance was not affected in this study.

In agreement with previous authors, IL-6 concentrations increased with exercise duration and peaked after exercise (Souglis et al. 2015). The prolonged nature of the exercise protocol likely explains the differences in the magnitude of post-exercise IL-6 responses (Table 1) compared to previous authors investigating intermittent exercise (Andersson et al. 2010; Souglis et al. 2015). Due to methodological limitations, the mechanism causing the increase in IL-6 concentrations could not be isolated but exercise intensity and duration (Gokhale et al. 2007), the occurrence of hypoglycaemia (Dotson et al. 2008) and supraphysiological doses of epinephrine (Helge et al. 2003) have been shown to modulate the circulatory appearance of IL- 6 or IL- 6 mRNA expression. Although likely attributable to the low dose of carbohydrate used $\left(\sim 20 \mathrm{~g} \mathrm{~h}^{-1}\right)$, no time $\times$ trial interaction effect was found for IL- 6 concentrations in the present study. Our data did indicate a trend for overall reduced IL-6 levels with PSE when compared to MDX and PLA, supporting the findings of Kraemer et al. (2015), albeit when isomaltulose was consumed with beta-hydroxy-beta-methylbutyrate in a recovery context. Carbohydrate provision may have important consequences for soccer performance in times of increased exercise volume as reduced glycogen availability, changes in calcium homeostasis and increased formation of reactive oxygen species can activate transcription factors which regulate IL-6 synthesis (Fischer 2006).

Ingesting fluid in a manner representing better ecological validity than examined previously (i.e., at breakfast, during the warm-up and HT and before extra-time), resulted in post-exercise mass losses that exceeded $2 \%$ body mass. It, therefore, appears that despite players arriving in a fed and hydrated state and consuming $0.5 \mathrm{~L}$ of fluid with breakfast, and ingesting $0.4-0.5 \mathrm{~L} \mathrm{~h}^{-1}$ during exercise, such volumes were not enough to prevent mass losses during intermittent exercise performed in ambient temperatures. However, although post-hoc analyses were unable to isolate specific between-trial differences, abdominal discomfort values (Table 2) were lower for MDX and PSE when compared to PLA from 60 min onwards; findings which are contrary to those observed when substantial amounts of isomaltulose $\left(>60 \mathrm{~g} \mathrm{~h}^{-1}\right.$ ) were ingested before and during $2 \mathrm{~h}$ of cycling at $60 \%$ of maximum workload (Oosthuyse et al. 2015). Accordingly, such findings may have important implications for applied practitioners who may have previously been deterred from recommending low-GI carbohydrates before soccer-specific exercise due to the risk of elevating abdominal discomfort.

Ingesting carbohydrates at a rate of $\sim 20 \mathrm{~g} \mathrm{~h}^{-1}$ did not significantly attenuate reductions in physical (i.e., sprinting and jumping) or skilled (i.e., soccer shooting and dribbling) performances observed throughout $120 \mathrm{~min}$ of simulated match-play. For soccer skills, a speed-accuracy trade-off occurred as shooting and dribbling speed reduced throughout exercise. These findings are in contrast to those that have demonstrated ergogenic effects as a result of higher amounts of carbohydrate $\left(>40 \mathrm{~g} \mathrm{~h}^{-1}\right)$ ingested more frequently (Ali and Williams 2009; Russell et al. 2012). Although regular fluid-ingestion does not align with the hydro-nutritional strategies of competing soccer players, it is likely that reduced opportunities to ingest carbohydrate in fluid form likely precluded players from achieving ergogenic thresholds of consumption (Ali and Williams 2009; Russell and Kingsley 2014). Therefore, when limited opportunities exist to consume fluids containing carbohydrates, such strategies may be supplemented by alternative modes of carbohydrate provision such as gels (Harper et al. 2016a) or by using greater concentrations of carbohydrate solution (Harper et al. 2017). Consideration should, however, still be given to the GI of the carbohydrates consumed (Kingsley et al. 2014).

In addition to the performance decrements seen over the 120-min protocol, transient reductions in physical and skilled performance occurred at the start of the second half as indicated by reduced shot speed and jump height. Therefore, strategies which maintain body temperature over the HT period may be efficacious at the onset of the second half (Russell et al. 2015c). Although markers of muscle and core temperature were not recorded in this study, previous findings show that reductions in jump performance, attributable to losses in core temperature (and likely muscle temperature also), occur throughout a simulated HT break (Russell et al. 2015b). Speculatively, body temperature losses may also explain the observed decrements in skilled as well as physical performances at the onset of the second half.

\section{Conclusions}

In conclusion, this study aimed to examine the physiological and performance effects of high- and low-GI carbohydrates consumed at two time-points before and during 120 min of simulated soccer-specific exercise. Although provision of $\sim 20 \mathrm{~g} \mathrm{~h}^{-1}$ of carbohydrate, from either highor low-GI sources did not attenuate reductions in markers of physical or skill performance, blood glucose concentrations were better maintained throughout exercise and the magnitude of the exercise-induced rebound glycaemic 
response was lowered in PSE when compared to MDX. Furthermore, isomaltulose proved more effective in lowering the epinephrine response to prolonged exercise. Therefore, when limited opportunities exist to consume fluids during exercise, the consumption of low-GI isomaltulose before soccer-specific exercise may offer an alternative to the use of high-GI carbohydrates (e.g. maltodextrin). Notably, such responses were observed in players who commenced exercise in a fed and hydrated state, and who consumed treatment beverages in a manner that reflects the competitive practices of professional athletes (i.e., ingestion before exercise and at HT). Thus, the match-day practices of soccer players may be modified to include low-GI carbohydrate consumption.

Acknowledgements This study was funded by BENEO GmbH, Mannheim, Germany, a member of the Südzucker Group. The results of the study are presented clearly, honestly, and without fabrication, falsification, or inappropriate data manipulation. We wish to thank Sport Central (Newcastle-upon-Tyne) for facility use.

\section{Compliance with ethical standards}

Ethical standards This study was approved by an appropriate ethics committee and has therefore been performed in accordance with the ethical standards laid down in the 1964 Declaration of Helsinki and its later amendments. All participants provided written informed consent prior to any participation.

Conflict of interest Authors MR and ES received a Grant from BENEO GmbH to complete this work. The study results and data contained in this publication have been developed by and/or for BENEO of which authors AH and ST are employees. BENEO reserves the exclusive right to use the results and data for possible Health Claim requests.

Open Access This article is distributed under the terms of the Creative Commons Attribution 4.0 International License (http://creativecommons.org/licenses/by/4.0/), which permits use, duplication, adaptation, distribution and reproduction in any medium or format, as long as you give appropriate credit to the original author(s) and the source, provide a link to the Creative Commons license and indicate if changes were made.

\section{References}

Ali A, Williams C (2009) Carbohydrate ingestion and soccer skill performance during prolonged intermittent exercise. J Sports Sci 27:1499-1508

Andersson H, Bohn SK, Raastad T, Paulsen G, Blomhoff R, Kadi F (2010) Differences in the inflammatory plasma cytokine response following two elite female soccer games separated by a 72-h recovery. Scand J Med Sci Sports 20:740-747

Atkinson FS, Foster-Powell K, Brand-Miller JC (2008) International tables of glycemic index and glycemic load values: 2008. Diabetes Care 31:2281-2283

Balijepalli C, Druyts E, Siliman G, Joffres M, Thorlund K, Mills EJ (2017) Hypoglycemia: a review of definitions used in clinical trials evaluating antihyperglycemic drugs for diabetes. Clin Epidemiol 9:291-296

Bangsbo J, Iaia FM, Krustrup P (2007) Metabolic response and fatigue in soccer. Int J Sports Physiol Perform 2:111-127

Borg GAV (1973) Perceived exertion—note on history and methods. Med Sci Sports Exerc 5:90-93

Chryssanthopoulos C, Hennessy LC, Williams C (1994) The influence of pre-exercise glucose ingestion on endurance running capacity. Br J Sports Med 28:105-109

Clarke ND, Drust B, Maclaren DP, Reilly T (2008) Fluid provision and metabolic responses to soccer-specific exercise. Eur J Appl Physiol 104:1069-1077

Convertino VA, Armstrong LE, Coyle EF, Mack GW, Sawka MN, Senay LC, Sherman WM (1996) American College of Sports Medicine position stand-exercise and fluid replacement. Med Sci Sports Exerc 28:R1-R7

Costill DL, Coyle E, Dalsky G, Evans W, Fink W, Hoopes D (1977) Effects of elevated plasma FFA and insulin on muscle glycogen usage during exercise. J Appl Physiol Respir Environ Exerc Physiol 43:695-699

Coyle EF, Coggan AR, Hemmert MK, Ivy JL (1986) Muscle glycogen utilization during prolonged strenuous exercise when fed carbohydrate. J Appl Physiol 61:165-172

Dahlqvist A, Auricchio S, Semenza G, Prader A (1963) Human intestinal disaccharidases and hereditary disaccharide intolerance. The hydrolysis of sucrose, isomaltose, palatinose (isomaltulose), and a 1,6-alpha-oligosaccharide (isomalto-oligosaccharide) preparation. J Clin Invest 42:556-562

Dotson S, Freeman R, Failing HJ, Adler GK (2008) Hypoglycemia increases serum interleukin-6 levels in healthy men and women. Diabetes Care 31:1222-1223

Febbraio MA, Lambert DL, Starkie RL, Proietto J, Hargreaves M (1998) Effect of epinephrine on muscle glycogenolysis during exercise in trained men. J Appl Physiol (1985) 84:465-470

Felig P, Cherif A, Minagawa A, Wahren J (1982) Hypoglycemia during prolonged exercise in normal men. N Engl J Med 306:895-900

Fischer CP (2006) Interleukin-6 in acute exercise and training: what is the biological relevance? Exerc Immunol Rev 12:6-33

Foskett A, Williams C, Boobis L, Tsintzas K (2008) Carbohydrate availability and muscle energy metabolism during intermittent running. Med Sci Sports Exerc 40:96-103

Fritzsche RG, Switzer TW, Hodgkinson BJ, Lee SH, Martin JC, Coyle EF (2000) Water and carbohydrate ingestion during prolonged exercise increase maximal neuromuscular power. J Appl Physiol 88:730-737

Gokhale R, Chandrashekara S, Vasanthakumar KC (2007) Cytokine response to strenuous exercise in athletes and non-athletes-an adaptive response. Cytokine 40:123-127

Harper LD, West DJ, Stevenson E, Russell M (2014) Technical performance reduces during the extra-time period of professional soccer match-play. PLoS One 9:e110995

Harper LD, Briggs MA, McNamee G, West DJ, Kilduff LP, Stevenson E, Russell M (2016a) Physiological and performance effects of carbohydrate gels consumed prior to the extra-time period of prolonged simulated soccer match-play. J Sci Med Sport 19:509-514

Harper LD, Hunter R, Parker P et al (2016b) Test-retest reliability of physiological and performance responses to $120 \mathrm{~min}$ of simulated soccer match-play. J Strength Cond Res 30:3178-3186

Harper LD, Stevenson EJ, Rollo I, Russell M (2017) The influence of a $12 \%$ carbohydrate-electrolyte beverage on self-paced soccerspecific exercise performance. J Sci Med Sport

Helge JW, Stallknecht B, Pedersen BK, Galbo H, Kiens B, Richter EA (2003) The effect of graded exercise on IL-6 release and glucose uptake in human skeletal muscle. J Physiol 546:299-305 
Jentjens RL, Jeukendrup AE (2003) Effects of pre-exercise ingestion of trehalose, galactose and glucose on subsequent metabolism and cycling performance. Eur J Appl Physiol 88:459-465

Kingsley M, Penas-Ruiz C, Terry C, Russell M (2014) Effects of carbohydrate-hydration strategies on glucose metabolism, sprint performance and hydration during a soccer match simulation in recreational players. J Sci Med Sport 17:239-243

Kraemer WJ, Hooper DR, Szivak TK et al (2015) The addition of betahydroxy-beta-methylbutyrate and isomaltulose to whey protein improves recovery from highly demanding resistance exercise. J Am Coll Nutr 34:91-99

Krustrup P, Mohr M, Steensberg A, Bencke J, Kjaer M, Bangsbo J (2006) Muscle and blood metabolites during a soccer game: implications for sprint performance. Med Sci Sports Exerc 38:1165-1174

MacDonald I, Daniel JW (1983) The bio-availability of isomaltulose in man and rat. Nutr Rep Int 28:1089-1090

Oosthuyse T, Carstens M, Millen AM (2015) Ingesting isomaltulose versus fructose-maltodextrin during prolonged moderate-heavy exercise increases fat oxidation but impairs gastrointestinal comfort and cycling performance. Int J Sport Nutr Exerc Metab $25: 427-438$

Ramsbottom R, Brewer J, Williams C (1988) A progressive shuttle run test to estimate maximal oxygen uptake. Br J Sports Med 22:141-144

Rowlands DS, Thorburn MS, Thorp RM, Broadbent S, Shi X (2008) Effect of graded fructose coingestion with maltodextrin on exogenous 14C-fructose and 13C-glucose oxidation efficiency and highintensity cycling performance. J Appl Physiol 104:1709-1719

Russell M, Kingsley M (2014) The efficacy of acute nutritional interventions on soccer skill performance. Sports Med 44:957-970

Russell M, Benton D, Kingsley M (2010) Reliability and construct validity of soccer skills tests that measure passing, shooting, and dribbling. J Sports Sci 28:1399-1408
Russell M, Benton D, Kingsley M (2011a) The effects of fatigue on soccer skills performed during a soccer match simulation. Int J Sports Physiol Perform 6:221-233

Russell M, Rees G, Benton D, Kingsley M (2011b) An exercise protocol that replicates soccer match-play. Int J Sports Med 32:511-518

Russell M, Benton D, Kingsley M (2012) Influence of carbohydrate supplementation on skill performance during a soccer match simulation. J Sci Med Sport 15:348-354

Russell M, Benton D, Kingsley M (2014) Carbohydrate ingestion before and during soccer match play and blood glucose and lactate concentrations. J Athl Train 49:447-453

Russell M, Sparkes W, Northeast J, Kilduff LP (2015a) Responses to a 120 min reserve team soccer match: a case study focusing on the demands of extra-time. J Sport Sci 33:2133-2139

Russell M, West DJ, Bracken RM, Briggs MA, Giroud T, Cook CJ, Kilduff LP (2015b) A passive heat maintenance strategy implemented during a simulated half-time improves lower body power output and repeated sprint ability in professional Rugby Union players. Plos One 18:e0119374

Russell M, West DJ, Harper LD, Cook CJ, Kilduff LP (2015c) Halftime strategies to enhance second-half performance in team-sports players: a review and recommendations. Sports Med 45:353-364

Smith TJ, Wilson MA, Karl JP et al (2016) Interstitial glucose concentrations and hypoglycemia during 2 days of caloric deficit and sustained exercise: a double-blind, placebo-controlled trial. J Appl Physiol (1985) 121:1208-1216

Souglis A, Papapanagiotou A, Bogdanis GC, Travlos A, Apostolidis N, Geladas N (2015) Comparison of inflammatory responses to a soccer match between elite male and female players. J Strength Cond Res 29:1227-1233

Thomas DT, Erdman KA, Burke LM (2016) American College of Sports Medicine Joint Position Statement. Nutrition and athletic performance. Med Sci Sports Exerc 48:543-568 